\title{
EXPRESSION OF ER/PR/HER2, BASAL MARKERS AND ADHESION MOLECULES IN PRIMARY BREAST CANCER AND IN LYMPH NODES METASTASES: A COMPARATIVE IMMUNOHISTOCHEMICAL ANALYSIS
}

\author{
Agnieszka Adamczyk ${ }^{1}$, Joanna Niemiec ${ }^{1}$, Aleksandra Ambicka $^{2}$, Krzysztof Maeecki ${ }^{3}$, \\ WOJCIECH H. WYSOCKI ${ }^{4}$, JERZY Mituś ${ }^{4}$, JANUSZ RYŚ ${ }^{2}$
}

\author{
1Department of Applied Radiobiology, Centre of Oncology - Maria Skłodowska-Curie Memorial Institute, \\ Cracow Branch, Poland \\ 2Department of Tumour Pathology, Centre of Oncology - Maria Skłodowska-Curie Memorial Institute, \\ Cracow Branch, Poland \\ 3Department of Radiotherapy, University Children Hospital of Cracow \\ ${ }^{4}$ Department of Surgical Oncology, Centre of Oncology - Maria Skłodowska-Curie Memorial Institute, \\ Cracow Branch, Poland
}

\begin{abstract}
The immunophenotypic differences between primary and metastatic tumour cells could influence patient's treatment or/and the results of selected diagnostic procedures.

That prompted us to investigate potential differences between primary tumours and corresponding synchronous lymph node metastases in the $\mathrm{T} \geq 1 / \mathrm{N}+/ \mathrm{M} 0$ breast cancer patients. The investigated group consisted of 108 patients with invasive ductal breast cancer, who underwent radical surgery. The expression of ER, PR, HER2 as well as CK5/6, P-cadherin, EGFR and Ep-CAM was assessed immunohistochemically.

Our data suggest that ER, PR, HER2, EGFR and CK5/6 are expressed conservatively, with some minor changes between primary tumour and simultaneous lymph node metastases. On the contrary, Ep-CAM and P-cadherin immunoreactivity in primary and metastatic cells varied significantly. This variation might exclude Ep-CAM and $\mathrm{P}$-cadherin as potential diagnostic or therapeutic targets.
\end{abstract}

Key words: primary breast tumour, lymph node metastasis, basal markers, adhesion molecules.

\section{Introduction}

Breast cancer encompasses several pathological and molecular subtypes characterized by different outcomes and responses to a given treatment. Moreover, tumour texture is heterogeneous and consists of different cell clones. Each cell clone can present different proliferation rate, expression of particular markers and different metastatic potential. These clones might appear during cancer progression, hence it is possible that metastases are formed by a tumour subclone with a different immunophenotype than that presented by the majority of tumour cells. On the other hand, at least some (genetic/epigenetic) changes occur very early during carcinogenesis and therefore they might be maintained during later stages of carcinogenesis and even in the secondary tumour site [1-4]. So far it is not obvious if expression of potentially prognostic markers is stable in all tumour localizations.

Nowadays, the lymph node status, tumour size, histological grade, Ki67 proliferation index of cancer cells, status of HER2 and steroid receptors are well-established prognostic and predictive factors for breast cancer [5]. Routinely, the above-mentioned parameters are 
assessed with respect to primary tumours and the decision on neoadjuvant or adjuvant treatment is based on the obtained results. The differences in immunophenotypes between primary and metastatic tumour cells could influence the results of patient's treatment. Generally, patients with estrogen receptornegative tumours do not receive endocrine therapy, however, if expression of this protein would appear in metastases, patients might respond to that kind of treatment. On the other hand, formation of metastases by a tumour clone without HER2 amplification might result in no or little benefit from trastuzumab administration.

Recently, studies have been conducted to create antibodies which can be used in imaging procedures, such as positron emission tomography (PET) [6] or visualization in near-infrared [7]. The differences in the expression of some target proteins between primary tumours and metastases may entail problems for new diagnostic imaging procedures based on antibodies targeting these proteins. The most frequently studied targets are epithelial cell adhesion molecule (Ep-CAM), epidermal growth factor receptor (EGFR) and human epidermal growth factor receptor 2 (HER2) [6-8].

The above-mentioned arguments prompted us to investigate the differences between primary tumours and corresponding synchronous lymph node metastases in $\mathrm{T} \geq 1, \mathrm{~N}+, \mathrm{M} 0$ breast cancer patients. Expression of estrogen receptor (ER), progesterone receptor (PR), HER2 as well as cytokeratin 5 and 6 (CK5/6), P-cadherin, EGFR and Ep-CAM was assessed immunohistochemically.

\section{Material and methods}

\section{Patients}

The investigated group consists of 108 patients with invasive ductal breast cancer $(\mathrm{T} \geq 1, \mathrm{~N}+, \mathrm{M} 0)$, who underwent radical mastectomy between 2001 and 2005 at the Department of Surgical Oncology, Centre of Oncology, Cracow Branch. The mean age of patients was 53.6 \pm 0.9 (SE) (range 24.0-73.0) years. Clinical and histological data are summarized in Table I. The Local Ethics Committee has approved the study.

\section{Material}

Archival specimens from primary tumour and synchronous lymph node metastasis were reviewed independently by two pathologists to confirm the histological diagnosis and tumour grade.

\section{Immunohistochemical staining}

Sections from tissue samples fixed in $10 \%$ neutral buffered formalin and embedded in paraffin were cut at $4 \mu \mathrm{m}$, mounted on SuperFrost ${ }^{\circledR}$ Plus (Menzel-Glä- ser, Germany) slides, and then deparaffinized and hydrated through a series of xylenes and alcohols.

Following the antigen retrieval (Table II), slides were incubated in $3 \% \mathrm{H}_{2} \mathrm{O}_{2}$ diluted in methanol for $30 \mathrm{~min}$. After being washed, the slides were treated for $20 \mathrm{~min}$. with $2.5 \%$ horse normal serum, then incubated overnight with primary antibody at $4^{\circ} \mathrm{C}$ (in case of $\mathrm{P}$-cadherin the incubation at $37^{\circ} \mathrm{C}$ lasted only $1 \mathrm{~h}$ ). Sections were treated with the BrightVision detection system (Immunologic, Duiven, The Netherlands) and DAB (Vector Laboratories, Inc., Burlingame, USA) for protein visualization. Hematoxylin was used for nuclear counterstaining. Detailed information on immunohistochemistry and the number of stained/immunopositive slides is presented in Table II.

Moreover, PR/HER2 and EGFR/Ep-CAM were visualized using a double staining procedure. PR and EGFR were detected using VIP (Vector Laboratories, Inc., Burlingame, USA), while HER2 and Ep-CAM using DAB. Eventually, slides were counterstained with

Table I. Clinicopathological characteristics of 108 ductal breast cancer patients

\begin{tabular}{|c|c|}
\hline PARAMETER & $\mathbf{N}(\%)$ \\
\hline \multicolumn{2}{|l|}{$\mathbf{T}$} \\
\hline 1 & $17(15.7)$ \\
\hline 2 & $87(80.6)$ \\
\hline 3 & $4(3.7)$ \\
\hline \multicolumn{2}{|l|}{ Grade* } \\
\hline 1 & $13(12.2)$ \\
\hline 2 & $36(34.0)$ \\
\hline 3 & $57(53.8)$ \\
\hline \multicolumn{2}{|l|}{ Mastectomy } \\
\hline Patey/Madden & $105(97.2)$ \\
\hline Halsted & $3(2.8)$ \\
\hline \multicolumn{2}{|l|}{ Chemotherapy } \\
\hline not administered & - \\
\hline anthracyclines & $32(29.6)$ \\
\hline anthracyclines + taxanes & $62(57.4)$ \\
\hline taxanes & $8(7.4)$ \\
\hline other & $6(5.6)$ \\
\hline \multicolumn{2}{|l|}{ Hormonal therapy } \\
\hline not administered & $34(31.4)$ \\
\hline tamoxifen & $42(38.9)$ \\
\hline tamoxifen + aromatase inhibitor & $28(25.9)$ \\
\hline tamoxifen + GNRH analogue & $2(1.9)$ \\
\hline aromatase inhibitor & $2(1.9)$ \\
\hline \multicolumn{2}{|l|}{ Trastuzumab } \\
\hline not administered & $106(98.1)$ \\
\hline administered & $2(1.9)$ \\
\hline
\end{tabular}


Table II. Detailed information on immunohistochemical staining

\begin{tabular}{|c|c|c|c|c|c|c|c|}
\hline \multirow[t]{2}{*}{ ANTIGEN } & \multirow[t]{2}{*}{ Clone } & \multirow[t]{2}{*}{ MANUFACTURER } & \multirow[t]{2}{*}{$\begin{array}{l}\text { ANTIGEN } \\
\text { RETRIEVAL }\end{array}$} & \multirow[t]{2}{*}{ Dilution } & \multirow[t]{2}{*}{$\begin{array}{c}\text { POD } \\
\text { SUBSTRATE }\end{array}$} & \multicolumn{2}{|c|}{$\begin{array}{c}\text { NUMBER OF STAINED CASES/ } \\
\text { NUMBER OF POSITIVELY } \\
\text { STAINED CASES }\end{array}$} \\
\hline & & & & & & TUMOUR & LYMPH NODE \\
\hline $\mathrm{ER} \alpha$ & $6 \mathrm{~F} 11$ & Leica Biosystems 1 & \multirow{6}{*}{$\begin{array}{l}\text { TRS, } \mathrm{pH}=6.1 \\
\mathrm{DAKO}^{2} \\
50 \text { min., } 96^{\circ} \mathrm{C}\end{array}$} & $1: 100$ & $\mathrm{DAB}^{5}$ & $91 / 61$ & $93 / 62$ \\
\hline PR & $\mathrm{PGR} / 2$ & Leica Biosystems 1 & & $1: 200$ & VIP5 & $89 / 40$ & $93 / 39$ \\
\hline HER2 & - & $\mathrm{DAKO}^{2}$ & & $1: 250$ & $\mathrm{DAB}$ & $94 / 15$ & $93 / 12$ \\
\hline $\mathrm{CK} 5 / 6$ & $\mathrm{D} 5 / 16 \mathrm{~B} 4$ & $\mathrm{DAKO}^{2}$ & & $1: 50$ & $\mathrm{DAB}$ & $100 / 26$ & $101 / 25$ \\
\hline CK5 & XM26 & Thermo $^{3}$ & & $1: 80$ & & & \\
\hline P-cadherin & 56 & $\mathrm{BD}^{4}$ & & $1: 200$ & $\mathrm{DAB}$ & $103 / 46$ & $101 / 22$ \\
\hline EGFR & $\mathrm{H} 11$ & $\mathrm{DAKO}^{2}$ & \multirow{2}{*}{$\begin{array}{l}\text { Proteinase } \mathrm{K}, \\
10 \mathrm{~min} ., 37^{\circ} \mathrm{C}\end{array}$} & $1: 200$ & VIP & $91 / 7$ & $94 / 5$ \\
\hline Ep-CAM & VU-1D9 & Leica Biosystems ${ }^{1}$ & & $1: 50$ & $\mathrm{DAB}$ & $90 / 84$ & $94 / 81$ \\
\hline
\end{tabular}

Methyl Green (Vector Laboratories, Inc., Burlingame, USA).

The internal positive controls were positively stained cells of normal ducts and lobules for ER $\alpha, P R$, CK5/6, CK5 and P-cadherin. A tumour specimen with a known strong HER2 $(3+)$ expression and EGFR expression (external positive control) was added to each series of staining.

\section{IHC evaluation}

IHC staining was evaluated in the invasive component of the tumours, only. ER $\alpha$ (Fig. 1B) and PR expression were considered positive if more than $1 \%$ of tumour cells showed nuclear immunopositivity. Only tumours with complete strong membranous HER2 (Fig. 1C) or Ep-CAM (Fig. 1E) staining of $>30 \%$ of cells $(3+)$ were considered positive. P-cadherin (Fig. 1G) immunopositivity was defined as complete strong membranous staining observed in $>10 \%$ of cells or strong cytoplasmic staining in $>50 \%$ of cells. The expression of CK5/6 and CK5 (Fig. 1I) and EGFR was considered positive if more than $1 \%$ of the tumour cell was found to be immunoreactive.

In case of ER $\alpha, P R$, EGFR, HER 2 and CK5/6 a binary scale was used to evaluate staining results: 0 - negative, 1 - positive. Ep-CAM and P-cadherin expression was assessed using three categories: $0-$ negative, 1 - weak staining, 2 - strong staining.

We compared the expression of ER, PR, EGFR, HER2, CK5/6, Ep-CAM and P-cadherin in primary tumour and corresponding lymph node metastasis. In order to evaluate the differences in the intensity of marker expression the following mathematical formula was used: "change in marker expression $=$ expression in lymph node - expression in primary tumour". A result below 0 indicated a lower protein expression in the lymph node, a result equal to 0 - no changes in expression, while a result above 0 - more intense staining in the lymph node than in the tumour.

On the basis of the ER, PR and HER2 status, four immunophenotypes were distinguished: (1) luminal A (LA): ER + and PR + and HER2-, (2) luminal B (LB): $\mathrm{ER}+$ and $\mathrm{PR}+$ and HER2 + , (3) HER2 overexpressing $(\mathrm{HER} 2+)$ : ER - and PR- and HER2 +, (4) triple negative phenotype (TNP): ER- and PR- and HER2-.

\section{Statistical analysis}

Descriptive statistics were used to determine mean values and standard errors of means (SE). Associations between categorical variables were analysed using Pearson $\chi^{2}$ test. In all statistical procedures $\alpha<0.05$ was considered significant. Calculations were performed with the STATISTICA 9 software (StatSoft, Inc., Tulsa, KO 74104, USA).

\section{Results}

Detected changes in ER, PR, EGFR, HER2, CK5/6, Ep-CAM and P-cadherin expression are shown in Fig. 2. Over $90 \%$ of cases showed the same level of ER, PR, HER2, CK5/6 and EGFR expression in the primary tumour and nodal metastasis (Fig. 2). A high variation in staining intensity was found for Ep-CAM and P-cadherin (Fig. 2).

Eventually, we assessed relations between the frequency of spontaneous changes in the marker expression and the tumour grade or breast cancer subtype (Pearson $\chi^{2}$ ). We found that only differences in HER2 expression were statistically significantly related to subtype. All changes (reduction of expression) were noted in the LB subtype. Other results are presented in Table III. 



Fig. 1. Differences in the expression of ER, HER2, Ep-CAM, P-cadherin, CK5/6 and CK5 between primary breast cancer $(\mathrm{A}, \mathrm{C}, \mathrm{E}, \mathrm{G}, \mathrm{I})$ and lymph node metastasis $(\mathrm{B}, \mathrm{D}, \mathrm{F}, \mathrm{H}, \mathrm{J})$ (continued on the next page)

\section{Discussion}

Metastases are the main cause of death in breast cancer patients. The most popular model of metastasis formation assumes that the primary tumour is heterogeneous and only few cells obtain metastatic capacity.
However, some molecular data suggest that potential to create metastasis is a biological characteristics of all primary tumour cells and it is not a feature of rare cell clone with a metastatic phenotype [9]. This suggests that primary tumour and metastases share many genetic and epigenetic features. Confirmation 

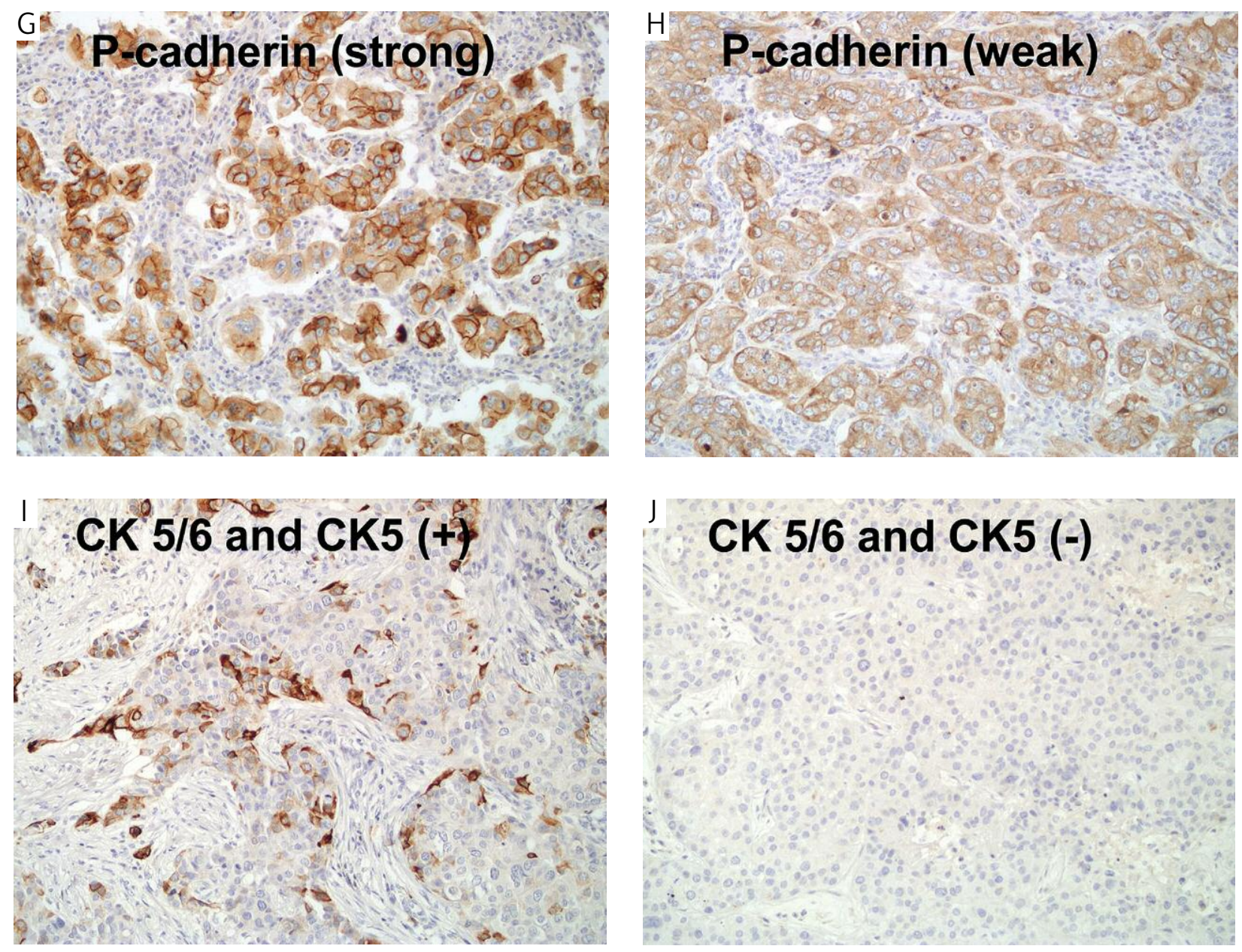

Fig. 1. Cont.

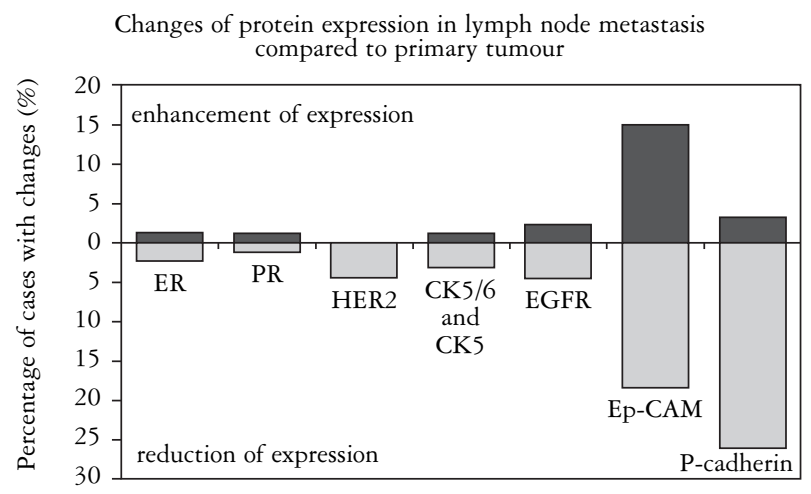

\begin{tabular}{|c|c|c|c|}
\hline & $\begin{array}{c}\text { REDUCTION } \\
\text { OF EXPRESSION } \\
\text { N (\%) }\end{array}$ & $\begin{array}{c}\text { LACK OF } \\
\text { CHANGES } \\
\text { IN EXPRES- } \\
\text { SION N (\%) }\end{array}$ & $\begin{array}{c}\text { ENHANCEMENT } \\
\text { OF EXPRESSION } \\
\mathbf{N}(\%)\end{array}$ \\
\hline $\mathrm{ER} \alpha$ & $2(2.3)$ & $83(96.5)$ & $1(1.2)$ \\
\hline PR & $1(1.2)$ & $84(97.6)$ & $1(1.2)$ \\
\hline HER2 & $4(4.5)$ & $85(95.5)$ & - \\
\hline $\begin{array}{l}\mathrm{CK} 5 / 6 \\
\text { and } \mathrm{CK} 5\end{array}$ & $3(3.2)$ & $89(95.7)$ & $1(1.1)$ \\
\hline P-cadherin & $25(26.1)$ & $68(70.8)$ & $3(3.1)$ \\
\hline EGFR & $4(4.5)$ & $83(93.3)$ & $2(2.2)$ \\
\hline Ep-CAM & $16(18.4)$ & $58(66.7)$ & $13(14.9)$ \\
\hline
\end{tabular}

Fig. 2. Representation of protein expression changes in lymph node metastasis in comparison to primary tumour

of the above-mentioned hypothesis is very important for future targeted therapies and diagnostic imaging strategies. In the last years many molecular targets were identified and many drugs with ability to target them were produced. Some of them, for example ER or HER2 blockers, have been used in clinical practice for years. Because the main goal of targeted therapy (systemic therapy) is to eliminate metastatic neoplastic cells, the above-mentioned therapies should be focused on secondary tumour sites. Therefore, a very important question arises whether the metastasizing cells differ from primary tumour cells. In our study we com- 
Table III. Differences between frequencies of events (changes of protein expression) observed in investigated categorical variables (grade, subtype) compared with Pearson $\chi^{2}$ test.

\begin{tabular}{|c|c|c|c|c|c|c|c|c|}
\hline \multirow{2}{*}{\multicolumn{2}{|c|}{$\begin{array}{l}\text { CHANGES IN PROTEIN EXPRESSION } \\
\text { IN LYMPH NODE METASTASES }\end{array}$}} & \multicolumn{3}{|c|}{ GRADE } & \multicolumn{4}{|c|}{ SUBTYPE } \\
\hline & & 1 & 2 & 3 & LA & LB & HER2 & TNP \\
\hline \multirow[t]{3}{*}{ ER } & reduction & 1 & 0 & 1 & 1 & 0 & 0 & 0 \\
\hline & lack of changes & 9 & 30 & 43 & 47 & 6 & 7 & 20 \\
\hline & enhancement & 0 & 0 & 1 & 1 & 0 & 0 & 0 \\
\hline \multirow[t]{3}{*}{$\mathrm{PR}$} & reduction & 0 & 0 & 1 & 1 & 0 & 0 & 0 \\
\hline & lack of changes & 10 & 28 & 45 & 48 & 6 & 7 & 23 \\
\hline & enhancement & 1 & 0 & 0 & 1 & 0 & 0 & 0 \\
\hline \multirow[t]{2}{*}{ HER2 } & reduction & 2 & 1 & $1 *$ & 0 & 4 & 0 & $0 * *$ \\
\hline & no changes & 9 & 30 & 45 & 52 & 3 & 7 & 23 \\
\hline \multirow[t]{3}{*}{ CK $5 / 6$} & reduction & 0 & 0 & 3 & 0 & 0 & 1 & 2 \\
\hline & lack of changes & 10 & 31 & 47 & 50 & 7 & 5 & 20 \\
\hline & enhancement & 0 & 1 & 0 & 0 & 0 & 0 & 0 \\
\hline \multirow[t]{3}{*}{ P-cadherin } & reduction & 2 & 8 & 14 & 13 & 1 & 3 & 5 \\
\hline & lack of changes & 9 & 24 & 35 & 39 & 6 & 4 & 15 \\
\hline & enhancement & 0 & 0 & 3 & 0 & 0 & 0 & 3 \\
\hline \multirow[t]{3}{*}{ EGFR } & reduction & 0 & 1 & 3 & 1 & 0 & 1 & 2 \\
\hline & lack of changes & 10 & 31 & 41 & 51 & 5 & 6 & 18 \\
\hline & enhancement & 0 & 0 & 2 & 0 & 0 & 0 & 2 \\
\hline \multirow[t]{3}{*}{ Ep-CAM } & reduction & 1 & 8 & 7 & 8 & 0 & 1 & 5 \\
\hline & lack of changes & 7 & 20 & 30 & 34 & 4 & 6 & 14 \\
\hline & enhancement & 1 & 2 & 10 & 7 & 1 & 0 & 4 \\
\hline
\end{tabular}

breast cancer subtype: $L A-E R+/ P R+/ H E R 2-, L B-E R+/ P R+/ H E R 2+, H E R 2-E R-/ P R-/ H E R 2+$, TNP (triple negative phenotype) - ER-/PR-/HER2

pared the expression of ER, PR, HER2 as well as CK5/6, P-cadherin, EGFR and Ep-CAM between primary tumours and synchronous lymph node metastases in breast cancer patients. We found a high percentage of accordance ( $>90 \%$ ) in the ER, PR, HER2, CK $5 / 6$ and EGFR expression pattern. Our results are consistent with other authors' studies $[10,11]$ reporting high concordance in steroid receptors status between primary tumour and lymph node metastasis. Interesting data were presented by Bogina et al. [12], who investigated primary tumours matched with local recurrence and distant metastasis (synchronous and metachronous), and found that the ER status was more conservative and was not affected by therapy, while PR status was influenced by adjuvant chemotherapy combined with hormonal therapy. Additionally, changes in PR expression were more frequent in distant metastases than in local recurrences [12].

The difference in HER2 expression between primary tumours and metastases is one of the most meticulously studied problem. We observed a discrepancy in HER2 expression in $4.5 \%$ of cases only. It is consistent with data from other authors, who noted high concordance (82.2-100\%) of HER2 status between primary tumour and lymph node metastases or distant metas- tasis $[11-15,19]$. However, some authors reported contradictory results [16-18]. Different time of occurrence and localization of metastases could explain these discrepancies. Santinelli et al. [16] showed differences in the HER2 status when primary tumours were compared to synchronous lymph node metastases $(6.7 \%)$, or to local recurrence (13.3\%), or to distant metachronous metastases (28.6\%). Moreover, Niikura et al. [17] reported that chemotherapy might influence the HER2 status in distant metastasis diagnosed after treatment. In chemotherapy-treated patients discordance was observed in $27 \%$, while in chemotherapy naïve patients - only in $10 \%$. It is also worth mentioning that patients with concordant HER2 status had a significantly longer overall survival [17].

In our study, the status of EGFR and CK5/6 was also very stable (concordance of $93.3 \%$ and $95.7 \%$, respectively), what confirms other authors' results, who found a high percentage of accordance in the EGFR expression between primary tumour and lymph node metastases $[10,13]$ or distant metastases [19]. There are very few studies investigating the expression of CK5/6, Ep-CAM and P- cadherin in primary tumour and metastasis $[20,21]$. In our study, Ep-CAM and P-cadherin expression was characterized by low con- 
cordance ( $66.7 \%$ and $70.8 \%$, respectively), which confirms some data reporting changes in the pattern of EpCAM expression in metastasis of head and neck squamous carcinoma [21].

Currently, the differences in the gene expression pattern between primary tumour and metastases are analysed using molecular techniques [22-25]. The results are still non-conclusive, what could be caused by analyzing heterogeneous groups of patients (different stage, grade, histology, treatment schedule) and different gene sets.

Our and other authors' studies suggest that ER, PR, HER2, EGFR and CK5/6 are expressed conservatively (with little changes in primary breast cancer and simultaneous lymph node metastases). However, EpCAM and P-cadherin expression varied considerably between primary tumour and nodal metastasis. This variation might exclude Ep-CAM and P-cadherin as potential diagnostic or therapeutic targets.

The study was supported by the Polish Ministry of Science and Higher Education; grant number NN401096137. The authors declare no conflict of interest.

\section{References}

1. Chen LC, Kurisu W, Ljung BM, et al. Heterogeneity for allelic loss in human breast cancer. J Natl Cancer Inst 1992; 84: 506-10.

2. Davidoff AM, Kerns BJ, Iglehart JD, et al. Maintenance of $\mathrm{p} 53$ alterations throughout breast cancer progression. Cancer Res 1991; 51: 2605-10.

3. Iglehart JD, Kerns BJ, Huper G, et al. Maintenance of DNA content and erbB-2 alterations in intraductal and invasive phases of mammary cancer. Breast Cancer Res Treat 1995; 34: 253-263.

4. Lacroix H, Iglehart JD, Skinner MA, et al. Overexpression of erbB-2 or EGF receptor proteins present in early stage mammary carcinoma is detected simultaneously in matched primary tumors and regional metastases. Oncogene 1989; 4: 145-51.

5. Goldhirsch A, Wood WC, Coates AS, et al. Strategies for subtypes - dealing with the diversity of breast cancer: highlights of the St, Gallen International Expert Consensus on the Primary Therapy of Early Breast Cancer 2011. Ann Oncol 2011; 22: 1736-1747.

6. Olafsen T, Sirk SJ, Olma S, et al. ImmunoPET using engineered antibody fragments: fluorine-18 labeled diabodies for same-day imaging. Tumour Biol 2012; 33: 669-677.

7. Wang K, Wang K, Li W, et al. Characterizing breast cancer xenograft epidermal growth factor receptor expression by using near-infrared optical imaging. Acta Radiol 2009; 50: 1095-1103.

8. Heine M, Freund B, Nielsen P, et al. High interstitial fluid pressure is associated with low tumour penetration of diagnostic monoclonal antibodies applied for molecular imaging purposes. PLoS One 2012; 7: e36258.

9. Ramaswamy S, Ross KN, Lander ES, et al. A molecular signature of metastasis in primary solid tumors. Nat Genet 2003; 33: 49-54.

10. Tsutsui S, Ohno S, Murakami S, et al. EGFR, c-erbB2 and p53 protein in the primary lesions and paired metastatic regional lymph nodes in breast cancer. Eur J Surg Oncol 2002; 28: 383-387.

11. D'Andrea MR, Limiti MR, Bari M, et al. Correlation between genetic and biological aspects in primary non-metastatic breast cancers and corresponding synchronous axillary lymph node metastasis. Breast Cancer Res Treat 2007; 101: 279-284.
12. Bogina G, Bortesi L, Marconi M, et al. Comparison of hormonal receptor and HER-2 status between breast primary tumours and relapsing tumours: clinical implications of progesterone receptor loss. Virchows Arch 2011; 459: 1-10.

13. Cho EY, Han JJ, Choi JL, et al. Comparison of Her-2, EGFR and Cyclin D1 in primary breast cancer and paired metastatic lymph nodes: an immunohistochemical and chromogenic in situ hybridization study. J Korean Med Sci 2008; 23: 1053-1061.

14. Gong Y, Booser DJ, Sneige N. Comparison of HER-2 status determined by fluorescence in situ hybridization in primary and metastatic breast carcinoma. Cancer 2005; 103: 1763-1769.

15. Aoyama K, Kamio T, Nishikawa T, et al. A comparison of HER2/neu gene amplification and its protein overexpression between primary breast cancer and metastatic lymph nodes. Jpn J Clin Oncol 2010; 40: 613-619.

16. Santinelli A, Pisa E, Stramazzotti D, et al. HER-2 status discrepancy between primary breast cancer and metastatic sites. Impact on target therapy. Int J Cancer 2008; 122: 999-1004.

17. Niikura N, Liu J, Hayashi N, et al. Loss of human epidermal growth factor receptor 2 (HER2) expression in metastatic sites of HER2-overexpressing primary breast tumors. J Clin Oncol 2012; 30: 593-599.

18. Āboliņ̌s A, Vanags A, Trofimovičs G, et al. Molecular subtype shift in breast cancer upon trastuzumab treatment: a case report. Pol J Pathol 2011; 62: 65-68.

19. Grupka NL, Lear-Kaul KC, Kleinschmidt-DeMasters BK, et al. Epidermal growth factor receptor status in breast cancer metastases to the central nervous system. Comparison with HER-2/ neu status. Arch Pathol Lab Med 2004; 128: 974-979.

20. Shao MM, Liu J, Vong JS, et al. A subset of breast cancer predisposes to brain metastasis. Med Mol Morphol 2011; 44: 1520.

21. Takes RP, Baatenburg de Jong RJ, Wijffels K, et al. Expression of genetic markers in lymph node metastases compared with their primary tumours in head and neck cancer. J Pathol 2001; 194 : 298-302.

22. Popławski AB, Jankowski M, Erickson SW, et al. Frequent genetic differences between matched primary and metastatic breast cancer provide an approach to identification of biomarkers for disease progression. Eur J Hum Genet 2010; 18: 560-568.

23. Ellsworth RE, Seebach J, Field LA, et al. A gene expression signature that defines breast cancer metastases. Clin Exp Metastasis 2009; 26: 205-213.

24. Weigelt B, Wessels LF, Bosma AJ, et al. No common denominator for breast cancer lymph node metastasis. Br J Cancer 2005; 93: 924-932.

25. Weigelt B, Glas AM, Wessels LF, et al. Gene expression profiles of primary breast tumors maintained in distant metastases. Proc Natl Acad Sci U S A 2003; 100: 15901-15905.

\section{Address for correspondence}

Agnieszka Adamczyk

Department of Applied Radiobiology,

Centre of Oncology - Maria Skłodowska-Curie

Memorial Institute, Cracow Branch

ul. Garncarska 11

31-115 Krakow, Poland

tel. +48124231073

fax +48124231076

e-mail: aa.adamczyk@yahoo.com 